\title{
Evaluation of efficacy of regimens containing zidovudine, stavudine and tinofovir
}

\author{
Adiga $\mathrm{S}^{1}$, Malawadi $\mathrm{BN}^{2}$, Adiga $\mathrm{U}^{3}$ \\ ${ }^{1}$ Dr Sachidananda Adiga, Associate Professor, Department of Pharmacology, ${ }^{2}$ Dr BN Malawadi, Assistant Professor, \\ Department of Biochemistry, ${ }^{3}$ Dr Usha Adiga, Associate Professor, Department of Biochemistry, all are affiliated with \\ Karwar Institute of Medical Sciences, Karwar, Karnataka, India.
}

Address for Correspondence: Dr. Usha Sachidananda Adiga, Associate Professor, Department of Biochemistry Karwar Institute of Medical Sciences, Karwar, Karnataka, India. E-mail: ushachidu@ yahoo.com

\begin{abstract}
Objective: Aim of the study, was to compare the efficacy of regimens containing zidovudine, stavudine and tinofovir by comparing CD4 counts of patients at the end of 2 years. We also aim to evaluate their efficacy, by comparing basal CD4 count and CD4 count at 2 years in patients on these three regimens. Methodology: A retrospective observational study was conducted on 128 HIV patients, receiving various antiretroviral regimens in a teaching hospital in coastal Karnataka. Data of patients who were diagnosed to be HIV positive, receiving HAART and were attending the hospital for regular follow up once in six months was collected in data extraction form. Regimens containing zidovudine, stavudine and tinofovir were evaluated by comparing 2 year CD4s of patients. Effectiveness of each regimen was evaluated by comparing basal CD4 count with CD4 count at the end of 2 years. Results: We did not find any significant difference in basal CD4 counts in 3 regimens. CD4 count at the end of 2 years differed significantly $(\mathrm{P}<0.05)$ between the groups. Stavudine receiving patients had significantly higher $(\mathrm{P}<0.05)$ CD4 count as compared to AZT treated patients. Patients treated with TDF had highly significant $(\mathrm{P}<0.0001)$ elevation in CD4 count compared to that of AZT. However d4T and TDF didn't have significant difference in CD4 counts at the end of 2 years. Patients in each group had extremely significant elevation in CD4 counts $(\mathrm{p}=0.0000)$ as compared to basal levels. Conclusion: We can conclude that TDF containing regimen is more effective than that containing AZT or d4T, based on the CD4 count at the end of 2 years and the extent of elevation of CD4 count.
\end{abstract}

Key words: AZT, d4T, TDF, CD4 count

\section{Introduction}

The sustained benefits of HAART have led to far greater numbers of HIV-1 infected cases receiving at least three drugs for greater periods of time. The Indian national AIDS control organization guidelines recommended the use of two nucleoside reverse transcriptase inhibitors (NRTI) in combination with a non-nucleoside reverse transcriptase (NNRTI) in India [1]. Zidovudine and lamivudine in combination with either nevirapine or efavirenz and stavudine, lamivudine in combination with nevirapine or efavirenz are commonly used regimens. However, nucleotide reverse transcriptase inhibitor is being popularly used in first line anti retroviral therapy [1].

Manuscript received $4^{\text {th }}$ June 2016

Reviewed: $15^{\text {th }}$ June 2016

Author Corrected: $28^{\text {th }}$ June 2016

Accepted for Publication $15^{\text {th }}$ July 2016
In resource limited settings, a number of factors have a role in choosing first line regimen. Cost of the drug, need for laboratory monitoring, severity of adverse drug reactions (ADRs) and its effectiveness are the determining factors. WHO had recommended stavudine (d4T) initially as it needed less laboratory monitoring and less price as compared to zidovudine (AZT) [2, 3]. Due to increasingly reported toxicities, WHO initially reduced dosage of $\mathrm{d} 4 \mathrm{~T}$ and later recommended tenofovirdisoproxilfumarate (TDF) as part of the preferred regimen, with AZT as an alternative [4, 5]. Despite this, d4T and AZT remain the first line regimen. Studies have reported an improvement in outcomes when the AZT and $\mathrm{d} 4 \mathrm{~T}$ containing regimens were switched over to TDF containing regimen in settings with limited resources [6, 7]. 
There are several studies which compare the effectiveness of different anti retro viral regimens. However there are limited numbers of studies, which evaluate more than two regimens in our setting. Hence we planned to evaluate the effectiveness of regimens containing AZT, d4T and TDF.

\section{Objectives}

Aim of the study, was to compare the efficacy of regimens containing zidovudine, stavudine and tinofovir by comparing CD4 counts of patients at the end of 2 years. We also aim to evaluate their efficacy, by comparing basal CD4 count and CD4 count at 2 years in patients on these three regimens.

\section{Methodology}

A retrospective observational study was conducted on 128 HIV patients, receiving various antiretroviral regimens in a teaching hospital of Karwar institute of medical sciences, Karwar, Karnataka, India. Institutional ethics committee approval was obtained prior to the commencement of the study.

Data of patients who were diagnosed to be HIV positive, receiving HAART and were attending the hospital for regular follow up once in six months was collected. Patients were evaluated during their scheduled follow up visits in detail, by measuring CD4 counts and other laboratory parameters serially once in 6 months. Patients receiving three different regimens at least for two years were included.

Exclusion: Data of patients with less than two year of treatment, deaths within 2 year were excluded.

Data Collection- Data collection form was used to extract data from Patient's medical records. Patient demography such as age, gender, medication prescribed (drug regimen), baseline CD4 cell counts, CD4 count values at 2 years were noted. Patient's data was categorized intothree groups based on the type of regimen.

- Group 1: zidovudine receiving [zidovudine, lamivudine, nevirapine (ZLN) or zidovudine, lamivudine, efavirenz (ZLE)]

- Group 2: stavudine receiving [stavudine, lamivudine, nevirapine (SLN) or stavudine, lamivudine, efavirenz (SLE)]

- Group 3: tenofovir receiving [tenofovir, lamivudine, nevirapine (TLN) ortenofovir, lamivudine, efavirenz (TLE)]

Standard drug dosages of the nucleoside reverse transcriptase inhibitors (NRTIs) were, zidovudine (AZT) $300 \mathrm{mg}$ twice daily, lamivudine (3TC) $150 \mathrm{mg}$ twice daily or $300 \mathrm{mg}$ once daily, stavudine (d4T) 60 mg daily.

Dosages of non-nucleoside reverse transcriptase inhibitors (NNRTIs) were nevirapine (NVP) $200 \mathrm{mg}$ once daily for a 2-week lead-in period and then as 200 $\mathrm{mg}$ twice daily and efavirenz (EFV) $600 \mathrm{mg}$ once daily. Nucleotide reverse transcriptase inhibitor (NtRTI), tinofovir (TDF), $300 \mathrm{mg}$ once daily was given in combination with lamivudine and either nevirapine or efavirenz. Demographic profile of patients are given in Table 1.

Regimens containing zidovudine, stavudine and tinofovir were evaluated by comparing 2 year CD4 counts of patients. Effectiveness of each regimen was evaluated by comparing basal CD4 count with CD4 count at the end of 2 years.

Statistical analysis was carried out using NCSS software. One way ANOVA was used to compare CD4 counts of all three groups at a time. Tukey Kramer's post test was used to compare the counts, taking two regimens at a time. CD4 counts before and after 2 years of therapy in individual groups were compared by Students paired t test.

\section{Results}

We did not find any significant difference in basal CD4 counts in 3 regimens. CD4 count at the end of 2 years differed significantly $(\mathrm{P}<0.05)$ between the groups. Stavudine receiving patients had significantly higher $(\mathrm{P}<0.05) \mathrm{CD} 4$ count as compared to zidovidine treated patients. Tinofovir treated patients had highly significant $(\mathrm{P}<0.0001)$ elevation in $\mathrm{CD} 4$ count compared to that of zidovudine.

However d4T and TDF didn't have significant difference in CD4 counts at the end of 2 years. The comparison of CD4 counts and demographic profile of patients are given in Table 1. Each group had extremely significant elevation in CD4 counts $(\mathrm{p}=0.0000)$ as compared to basal levels. 
Table-1: Comparison between patients on different regimens.

\begin{tabular}{|c|c|c|c|c|}
\hline & $\begin{array}{c}\text { Group 1 } \\
\text { (zidovudine) }\end{array}$ & $\begin{array}{c}\text { Group 2 } \\
\text { (stavudine) }\end{array}$ & $\begin{array}{c}\text { Group 3 } \\
\text { (tinofovir) }\end{array}$ & $\begin{array}{c}\text { P value comparing } \\
\text { 3 groups }\end{array}$ \\
\hline No of patients & 76 & 29 & 23 & - \\
\hline Gender (\%) & & & 26.1 & \\
Males & 62.84 & 51.72 & 73.9 & - \\
Females & 37.16 & 48.28 & $37.09 \pm 2.1$ & - \\
\hline Age in years & $38.93 \pm 0.86$ & $35.83 \pm 2.52$ & 182 & - \\
\hline Median basal CD4 & 234.5 & 141 & 547 & Not significant \\
\hline Median 2 year CD4 & 493 & 475 & $213.52 \pm 40.08$ & Not significant \\
\hline Mean basal CD4 \pm SEM & $250.74 \pm 18.07$ & $262.97 \pm 49.59$ & $606.22 \pm 65.08$ & - \\
\hline Mean 2 yr CD4 \pm SEMI & $533.67 \pm 35.8$ & $556.38 \pm 57.96$ & & \\
\hline
\end{tabular}

\section{Discussion}

We found significant difference in CD4 counts between the three groups. The increment in CD4 count was extremely significant $(\mathrm{p}=0.0000)$ as compared to basal CD4 count in all three groups.

Patients on Tinofovir had highest CD4 count levels and maximum extent of elevation (3.33 times the basal). Stavudine regimen receiving patients had 2.1 times elevation in CD4 count and 2.13 times increment was seen in patients on zidovudine regimen. Our study is supported by a report by Velen et al [8]. The similar pattern of elevation was reported in this study and he suggested that TDF is better than other two drugs.

We found better immunological response by d4T compared to AZT in our study. This is supported by a study, which reports an elevation in CD4 count with $\mathrm{d} 4 \mathrm{~T}$ regimen whereas decline in $\mathrm{CD} 4$ count with regimen containing AZT [9]. However controversial reports are also available. Report by Joly et al and Karelia et al suggest no significant difference in CD4 counts in patients receiving AZT and d4T [10,11]. Stavudine is reported to cause severe adverse reactions like lactic acidosis and hyper lactemia [12,13]. Severe anemia and neutropenia were associated with AZT $[14,15]$. AZT and $\mathrm{d} 4 \mathrm{~T}$ are less recommended compared to TDF as they are reported to be associated with severe toxicities [16]. Emnet et al and colleagues have reported the superiority of TDF compared to AZT [17]. In resource limited settings TDF regimen in first-line therapy instead of AZT. It might preserve future treatment options in absence of virological monitoring. Cost effectiveness analyses have pointed towards better clinical outcomes with TDF use compared with other NRTIs in industrialized and resource-limited settings [18-20]. Brennen and collegues have reported that TDF increases the regimen durability [21]. In settings with limited resources, switch over fromstavudine to tenofovir has been found to be slow due to cost of TDF [22] and management of associated toxicities, especially renal insufficiency [23], that occursin about $3 \%$ of the HIV population [24]. This necessitates the cost associated with more frequent laboratory monitoring of renal functions and cost associated with it. But Wyl and colleagues suggested that TDF was more cost effective and less virological failure as compared to AZT [25]. However choosing an ART regimen depends on factors like basal CD4 count and staging.

\section{Conclusion}

We can conclude that TDF containing regimen is more effective than that containing AZT or d4T, based on the CD4 count at the end of 2 years and the extent of elevation of CD4 count. Toxicities associated with these regimens have not been studied and that is the limitation of our study.

Acknowledgements-We thank Dr. Anand Pawaskar, Medical officer, ART center,Karwar.

Conflicts of interest: None

Funding: Nil

\section{References}

1. National AIDS Control Organization. Ministry of Health and Family Welfare, Government of India. 2009 August 26 [Last cited on 2010 Aug 31]. Available from: https://nacoonline.org/NACO.

2. Bender MA, Kumarasamy N, Mayer KH, Wang B, Walensky RP, Flanigan T, Schackman BR, Scott CA, Lu Z, Freedberg KA. Cost-effectiveness of tenofovir as first-line antiretroviral therapy in India. Clin Infect Dis. 2010 Feb 1;50(3):416-25. doi: 10.1086/649884. 
3. World Health Organization (2006) Antiretroviral therapy for HIV infecction inadults and adolescents in resource-limited settings: towards universal access.

4. World Health Organization (2010) Antiretroviral therapy for HIV infection inadults and adolescents: recommendations for a public health approach, 2010 revision.

5. World Health Organization (2007) Addendum to 2006 WHO Guidelines onantiretroviral therapy for HIV infection in adults and adolescents.

6. Chi BH, Mwango A, Giganti M, Mulenga LB, Tambatamba CB, et al. Early clinical and programmatic outcomes with tenofovir-based antiretroviral therapy in Zambia. J Acquir Immune DeficSyndr 2010; 54(1): 63-70. doi:10.1097/QAI.0b013e3181c6c65c

7. Bygrave H, Ford N, van Cutsem G, Hilderbrand K, Jouquet G, Goemaere E, Vlahakis N, Triviño L, Makakole L, Kranzer K. Implementing a tenofovirbased first-line regimen in rural Lesotho: clinical outcomes and toxicities after two years. J Acquir Immune Defic Syndr. 2011 Mar 1;56(3):e75-8. doi: 10.1097/QAI.0b013e3182097505.

8. Velen K, Lewis JJ, Charalambous S, Grant AD, Churchyard GJ, Hoffmann CJ. Comparison of tenofovir, zidovudine, or stavudine as part of first-line antiretroviral therapy in a resource-limited-setting: a cohort study. PLoS One. 2013 May 14;8(5):e64459. doi: 10.1371/journal.pone.0064459. Print 2013.

9. Umapathy S, ArunaP, Amar P and Kanjaksha G. CD4 count and viral load response to different anti retroviral treatment regimen among AIDS patients from Mumbai, WesternIndia. Retrovirology2009, 6 (Suppl 2):P81

10. VéroniqueJ, Philippe F, Vincent M, Françoise BV, Gastaut JA, Cecile G et al. Efficacy of Zidovudine Compared to Stavudine, Both in Combination with Lamivudine and Indinavir, in Human Immunodeficiency Virus-Infected NucleosideExperienced Patients with No Prior Exposure to Lamivudine, Stavudine, or Protease Inhibitors (Novavir Trial).Antimicrobial agents and chemotherapy 2002; 6 (18):1906-1913.doi:10.1128/AAC.46.6.19061913.2002

11. Karelia BN,Buch GJ. Treatment outcome of patients with HIV and TB.IJRPP 2012;1(2):151-158.
12. Osler M S, Stead D, Rebe KMeintjes G and Boulle et al. Risk factors for and clinical characteristics of severe hyperlactataemia in patients receiving antiretroviral therapy: a case-controlstudy. HIV Medicine 2010;11(2):121-129.doi: 10.1111/j.14681293.2009.00754.

13. Laurent C, Bourgeois A, Mpoudi-Ngolé E, Ciaffi L, Kouanfack C, Mougnutou R, Nkoué N, Calmy A, Koulla-Shiro S, Delaporte E. Tolerability and effectiveness of first-line regimens combining nevirapine and lamivudine plus zidovudine or stavudine in Cameroon. AIDS Res Hum Retroviruses. 2008 Mar;24(3):393-9. doi: 10.1089/aid.2007.0219.

14. Bae WH, Wester C, Smeaton LM, Shapiro RL, Lockman S, Onyait K, Thior I, Essex M. Hematologic and hepatic toxicities associated with antenatal and postnatal exposure to maternal highly active antiretroviral therapy among infants. AIDS. 2008 Aug 20;22(13):1633-40. doi: 10.1097/QAD. 0b013e $328307 \mathrm{a} 029$.

15. Curkendall SM, Richardson JT, Emons MF, Fisher AE, Everhard F. Incidence ofanaemia among HIVinfected patients treated with highly active antiretroviral therapy. HIV Medicine 2007;8(8):483-90.doi: 10.1111/j.1468-1293.2007.00500.x

16. Swapnil CJ, Jyoti RP, Vijay Motiram Motghare, Sudhir Laxmanrao Padwal et al. A prospective study, to determine adverse effects of anti-retroviralagents in rural tertiary care teaching hospital. Int J Basic ClinPharmacol. 2016 Jun;5(3):713-717.

17. Emnet KM, Lukman M, Muhammad NM, Marianti AM. Effectiveness of Tenofovir (TDF) / Emtricitabine (FTC) Versus Zidovudine (AZT) / Lamivudine (3TC) in Combination with Efavirenz (EFV) IN AntiretroviralNaive HIV-Infected Patients IN Eritrea International Journal of Pharmaceutical and Clinical Research 2015; 7(5): 364-67.

18. Bender MA, Kumarasamy N, Mayer KH, Wang B, Walensky RP, Flanigan T, Schackman BR, Scott CA, $\mathrm{Lu}$ Z, Freedberg KA. Cost-effectiveness of tenofovir as first-line antiretroviral therapy in India. Clin Infect Dis. 2010 Feb 1;50(3):416-25. doi: 10.1086/649884.

19. Jouquet G, Bygrave H, Kranzer K, Ford N, Gadot L, Lee J, Hilderbrand K, Goemaere E, Vlahakis N, Trivino L, Makakole L, Cleary S. Cost and cost-effectiveness of 
switching from d4T or AZT to a TDF-based first-line regimen in a resource-limited setting in rural Lesotho. $\mathrm{J}$ Acquir Immune Defic Syndr. 2011 Nov 1;58(3):e68-74. doi: 10.1097/QAI.0b013e31822a9f8d.

20. Bendavid E, Grant P, Talbot A, Owens DK, Zolopa A. Cost-effectiveness of antiretroviral regimens in the World Health Organization's treatment guidelines: a South African analysis. AIDS 2011; 25((2): 211-20. doi:10.1097/QAD.0AD. 0b013e328340fdf8.

21. Alana TB, Mhairi M, Prudence I, Kate S, Lawrence $\mathrm{L}$, Ian $\mathrm{S}$ et al, Increases in regimen durability associated with the introductionof tenofovir at a large public-sector clinic in Johannesburg, South Africa. Journal of the International AIDS Society 2013; 16(1):18794.doi:10. 7448/IAS.16.1.18794

22. Campaign for Access to Essential Medicines. 2008. Untangling the Webof Antiretroviral Price Reductions, 11th ed. Geneva: Me'decins sans Frontie` res. Available from: http://d2pd3b5abq75bb.cloudfront. net/2012 /07/16/14/49/04/691/UTW_11_ENG_Jul2008.pdf.

23. World Health Organization. Consolidated guidelines on the use ofantiretroviral drugs for treating and preventing HIV infection: recommendationsfor a public health approach. Geneva: World Health Organization; 2013.

24. Scherzer R, Estrella M, Li Y, Choi AI, Deeks SG, Grunfeld C, Shlipak MG. Association of tenofovir exposure with kidney disease risk in HIV infection. AIDS. 2012 Apr 24;26(7):867-75. doi: 10.1097/QAD. ob013e328351f68f.

25. von Wyl V, Cambiano V, Jordan MR, Bertagnolio S, Miners A, Pillay D, Lundgren J, Phillips AN. Costeffectiveness of tenofovir instead of zidovudine for use in first-line antiretroviral therapy in settings without virological monitoring. PLoS One. 2012;7(8):e42834. doi: 10.1371/journal.pone.0042834. Epub 2012 Aug 8.

\section{How to cite this article?}

Adiga S, Malawadi BN, Adiga U. Evaluation of efficacy of regimens containing zidovudine, stavudine and tinofovir. Int J Med Res Rev 2016;4 (7):1125-1129.doi: 10.17511/ijmrr.2016.i07.10. 